\title{
Methodologic Issues in the Use of Workers' Compensation Databases for the Study of Work Injuries With Days Away From Work. I. Sensitivity of Case Ascertainment
}

\author{
Arthur Oleinick, MD, JD, $\mathrm{MPH}^{1 *}$ and Brian Zaidman, BA $^{2}$
}

\begin{abstract}
Background Case ascertainment costs vary substantially between primary and secondary data sources. This review summarizes information on the sensitivity of state administrative databases in workers' compensation systems for the ascertainment of daysaway-from-work (DAFW) work injuries for use in modeling studies.

Methods Review of the literature supplemented by data from governmental or organizational reports or produced for this report.

Results Employers currently appear to provide workers' compensation insurance coverage for $98.9 \%$ of wage and salary workers. Wage and salary jobs account for approximately $90 \%$ of jobs in the United States. In industries such as manufacturing, the fraction of covered jobs is probably closer to 98\%. In Minnesota, the number of DAFW cases ascertained by the Bureau of Labor Statistics' annual survey of occupational injuries and illnesses is approximately $92-97 \%$ concordant with the number of wage compensation claims for injuries producing DAFW over the period 1992-2000, once adjustments are made to permit direct comparisons of the numbers. The workers' compensation databases provide information for more than $95 \%$ of the total DAFW resulting from work injuries. Covariate estimates are unaffected by this less than 5\% loss because effects appear dependent on time from injury.

Conclusions Statewide workers' compensation administrative databases can have substantial utility for epidemiologic study of work injuries with DAFW because of their size, using high sensitivity for case ascertainment as the evaluative criterion. Am. J. Ind. Med. 45:260-274, 2004. @ 2004 Wiley-Liss, Inc.
\end{abstract}

KEY WORDS: review; occupational disability; outcomes; work injuries; epidemiologic methods

\footnotetext{
${ }^{1}$ School of Public Health, University of Michigan, Ann Arbor, Michigan

${ }^{2}$ Research and Statistics, Department of Labor and Industry, State of Minnesota, St. Paul, Minnesota

Supported, in part by: Grant sponsor: CDC; Grant number: R01 OH003804-03

${ }^{*}$ Correspondence to: Arthur Oleinick, Occupational Health Program, Department of Environmental Health Sciences, School of Public Health, University of Michigan, Ann Arbor, Ml 48109. E-mail: aoleinic@umich.edu

Accepted 16 October 2003

DOl 10.1002/ajim.10333. Published online in Wiley InterScience

(www.interscience.wiley.com)
}

\section{INTRODUCTION}

Over the past decade, a number of investigators have employed generalized linear models to identify factors associated with prolonged days away from work (DAFW, used both as a noun and adjective for simplicity) following work injuries and illnesses by using data from state workers' compensation systems on the duration of wage replacement (indemnity) for such lost work-time. The advantages of using such databases are obvious - the databases are 
population-based with large numbers of cases, and covariate and outcome information is either already available in computer-usable format or can be made so by programming. Consequently, the cost per record is a fraction of that for a prospective study based on hard-copy record review or data collection. More recently, however, several investigators have expressed reservations about the use of such databases on a variety of methodologic grounds. This paper reviews existing data, as well as providing new data, on the sensitivity of case ascertainment for work injuries with DAFW when these cases are identified in a statewide workers' compensation database.

In 2001, the Federal Bureau of Labor Statistics (BLS) annual survey of occupational injuries and illnesses reported that some 1.5 million cases missed at least one workday (DAFW), not counting the day of injury, as a result of workrelated injury or illness. About $47 \%$ of this group had more than seven DAFW and were potentially eligible for wage compensation under the longest waiting period currently specified by statute of 7 days (22 states) [BLS, 2002, 2003c; OWCP, 2002]. The $47 \%$ is a minimum estimate because some of these states count the day of injury, non-workdays such as weekends and partial disability days toward the total required. This percentage translates into a lower bound estimate of some 722,000 potential wage indemnity cases, $89 \%$ of which were classified as due to traumatic injuries and disorders including repetitive stress disorders of the back and $11 \%$ as systemic diseases and disorders, including carpal tunnel syndrome, tendonitis, bursitis, dorsopathies, dermatitis, and herniae [BLS, 2003a]. Based on the 1986 Michigan compensable injury cohort (7 day waiting period) [Oleinick et al., 1993], the group given wage compensation for DAFW accounts for some $98 \%$ of lost work-time (missed worktime + restricted work-time) produced by occupational injuries.

The social and economic impact of DAFW attributable to occupational injuries and illnesses is substantial. Using Michigan cases compensated for 1986 injuries, Oleinick et al. [1993] estimated that workplace injuries and illnesses would produce some 420 million DAFW nationally during the course of their natural history. Leigh et al. [1997] using data for 1992, estimated that nonfatal workplace injuries and illnesses were responsible for $\$ 65.61$ billions in lost earnings, based on wage replacement costs. Taking into account the fact that Oleinick's estimate was extrapolated from the Michigan experience (7 day waiting period) while Leigh used a national estimate reflecting variations in state waiting periods and that the average weekly wage increased some $16 \%$ over the interval noted, the two estimates are consistent.

The present report reserves for a later paper in this series the question of the extent to which analyses of populations based on workers' compensation administrative systems can yield information that is helpful for tertiary interventions. At this time we are concerned with the issue of the fraction of eligible DAFW work-related injury or illness cases ascertainable in compensation databases. This inquiry focuses on data indicating the fraction of jobs covered by workers' compensation insurance and the fraction of injured workers eligible for compensation who actually receive such compensation. This paper addresses the sensitivity of ascertainment of cases for such systems.

\section{SENSITIVITY}

Estimation of the sensitivity of ascertainment of DAFW work injury cases by workers' compensation databases requires consideration of three data sets, each a sub-set of the previous one. The largest data set is defined as the number of jobs for which workers' compensation insurance is mandated by state statute. Here the issue is the extent of coverage and whether employers actually provide such mandated insurance for, without such coverage, there is no possibility of ascertainment. The second data set is defined as the sub-set of DAFW work injuries that meets the state's minimum waiting period for DAFW or days of partial disability for wage compensation eligibility. Here the issue is whether covariates based on the resulting censored populations are generally applicable. The third data set is defined as the fraction of eligible DAFW work injury cases that actually receives compensation payments. Here the issue is whether, for whatever reason, some eligible workers choose not to seek compensation or whether insurers deny claims that should be paid with the result that the potential study population is further censored raising questions again of generalizability of results. Each of these issues is discussed in the sections that follow.

\section{PART I-FRACTION OF WORKERS COVERED BY WORKERS' COMPENSATION INSURANCE}

Because workers' compensation falls under state jurisdiction, there are no uniform national reporting requirements that can be used to estimate the extent of coverage. Rather, annual estimates of the fraction of US jobs covered by workers' compensation have been derived using a number of federal surveys and private databases.

One way to estimate the covered fraction is to assume that all companies that are required to obtain coverage under law do so and then use federal survey data to estimate the fraction of covered jobs. In view of the serious adverse legal consequences of failing to obtain workers' compensation coverage when required-uninsured employers are subject to traditional negligence remedies by injured employees and these have the potential for very large judgments-the assumption seems reasonable. The first seven columns of Table I contain data that can be used to obtain an estimate with this approach. 


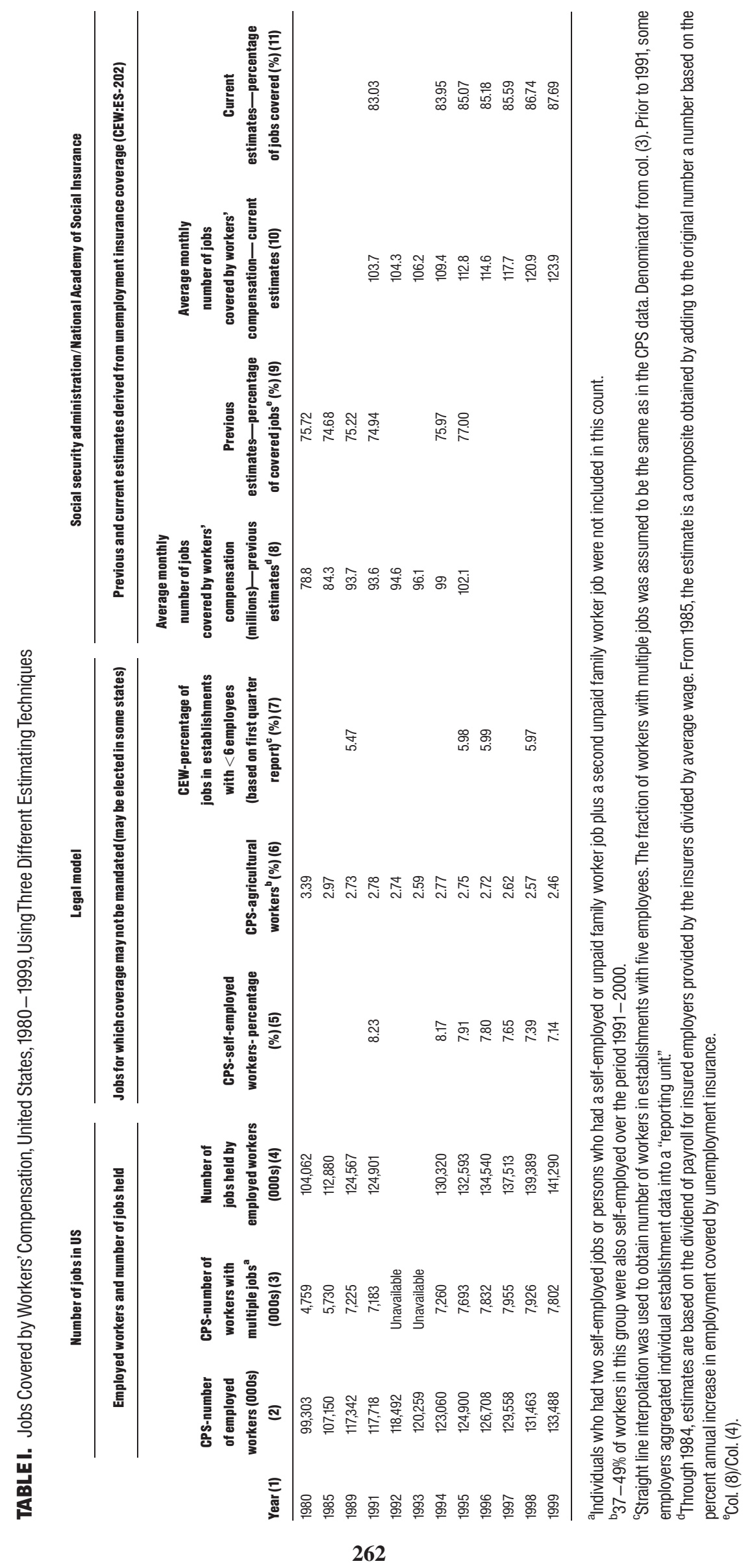


Columns 2-4 estimate the average annual number of jobs held by employed workers in the US. The number of employed workers is obtained from the Current Population Survey (CPS) [BLS, 2000], a monthly household survey of about 50,000 households conducted by the US Bureau of the Census for the US Bureau of Labor Statistics. In several years, in the interval noted, survey re-design and definition changes yield data that BLS indicates may not be "strictly" [2001e] comparable from year to year. However, the small differences in the total counts before and after such changes, and the relative stability of percentages shown in subsequent columns, indicate that such re-designs little affect the analysis of workers with multiple jobs (Columns 2-4) or the fractions of workers in jobs without mandatory coverage (Columns 5-7). The Table estimates the total number of jobs held by employed workers (column 4) by assuming two jobs for each employed worker who indicates that he/she had multiple jobs (column 3), although a small percentage have more than two jobs [Stinson, 1997; BLS, 2003b]. In 1995, with few exceptions, the fraction of workers with more than one job was less than $8 \%$ in all sub-groups when analyzed by two digit occupational codes (exception-professional specialty jobs) or by three digit industry codes (exceptionservice industries) [Amirault, 1997].

The fraction of covered jobs is computed by estimating the difference between all jobs and the sum of the fractions of workers in groups for whom coverage is not mandatory, though some employers in these groups may obtain coverage voluntarily. Columns 5-7 give the fraction of workers in occupational groups that are often excluded from mandatory coverage under state compensation laws. Columns 5 and 6 are based on CPS data and are derived from counts of workers in these categories. There is overlap in the data in these two columns because $37-49 \%$ of farmers are self-employed [BLS, 2001b]. Column 6 also includes some covered workers in companies that provide agricultural services and would require coverage, if the firms were large enough.

Column 7 gives the fraction of the workforce in the very smallest establishments ( $<6$ workers/establishment) and is based on BLS' series on covered employment and wages (CEW) [1999a]. This survey counts, by establishment, the number of jobs for which the employer pays unemployment insurance (workers with multiple jobs in different establishments are counted more than once), but does not count workers (approximately 12.3 millions in 1995) who are selfemployed, domestic workers, farmers, and the approximately $5 \%$ of state and government workers who are excluded from unemployment insurance coverage.

The percentage in column 7 clearly includes some workers who are covered, despite working in the smallest category of establishment size. First, an employer may have more than one establishment-defined as an economic unit that produces goods or provides services, is typically at a single physical location and engages in one, or predomi- nantly one, type of economic activity-[BLS, 1999a] and the aggregate employment in all locations may mandate coverage. Second, and quantitatively most important, only a minority of jurisdictions omit mandatory coverage for employers with fewer than six employees. In 1989 and 1998, 14 jurisdictions did not mandate coverage for companies with fewer than six employees. Nine of these jurisdictions were in the southeastern United States [Chamber of Commerce, 1999]. Third, some small employers obtain coverage voluntarily.

The combined total for the fractions of workers exempt from mandatory coverage in columns $5-7$ is approximately $16-17 \%$. Since this percentage likely over-estimates the actual percentage for the reasons noted and since the workers tabulated in columns 5-7 represent the major categories omitted from mandatory coverage by state statutes, the figure of $85 \%$ appears to represent a reasonable lower-bound estimate of the fraction of jobs covered by workers' compensation during at least the past decade. This estimate is consistent with the estimate in column 11 obtained by a second estimating procedure.

A corollary of the conclusion regarding the extent of coverage is that coverage is substantially higher than $85 \%$ in industries such as manufacturing with relatively few workers in the categories exempt from mandatory coverage. For example, in CEW data from 1995, 1.3\% of workers in manufacturing were employed in establishments with fewer than five workers compared to $4.2 \%$ in transportation and public utilities and $13.2 \%$ in construction (the three groups comprise $30.5 \%$ of the workforce in private industry). Considering that the number of self-employed workers in manufacturing is also quite low, this would indicate that the fraction of jobs in manufacturing industries that are not covered by workers' compensation is extremely low.

A second annual estimate of the fraction of jobs covered by workers' compensation was prepared by the Office of Research and Statistics at the Social Security Administration (SSA) under the direction of its Branch Chief, Mr. Jack Schmulovitz, and reported in the SSA's Annual Statistical Supplement (through 1991) [yearly] (columns 8-9). Schmulovitz updated the estimate through 1993 with the same methodology [1995]. The estimates for this period indicated that about $75 \%$ of workers were covered by workers' compensation insurance. Prior to 1985, the estimate was based on reports of covered-payroll amounts filed by compensation insurers divided by the average wage of workers covered by unemployment insurance as a proxy for the average wage of workers covered by workers' compensation. A review of articles published contemporaneously by members of the research group did not provide documentation for the strength of the proxy relationship [SSA (yearly); Price, 1980; Nelson, 1988, 1992; Schmulovitz, 1995]. Beginning in 1985, covered payroll was incomplete in some states. In the period 1985-1993, the estimate was based upon covered 
payroll in 1984, adjusted for subsequent changes in the number of workers covered by unemployment insurance.

In 1997, Schmulovitz used the former methods to provide a third set of estimates through 1995 and revised the method for estimating the fraction of jobs covered by workers' compensation in a report to the National Academy of Social Insurance (NASI) [Schmulowitz, 1997] (columns 10-11). In preparing his new estimates, Schmulovitz relied on state-by-state data on total and covered workers collected by the Office of Workers' Compensation Programs (OWCP) in the Department of Labor [OWCP, yearly]. The OWCP survey requests data from the states on the size of the state workforce and the number of workers covered by workers' compensation, but does not specify the methods to be used to obtain these estimates (Personal communication. Mr. Mark Grobman, OWCP, 2/5/01). Schmulovitz noted that the number of workers covered by workers' compensation exceeded $97 \%$ of workers covered by unemployment insurance during the same period and cited a similar estimate of $98+\%$ coverage reported by BLS based on 1996 data in the Economic Cost Index (ECI) survey. The ECI survey does not include counts for the self-employed, farm, household, or Federal Government workers [BLS, 1999b]. However, neither percentage cited by Schmulovitz was referenced to published reports that could be used to verify the percentages noted. For the period 1989-1995, the fraction of covered jobs was $83-85 \%$ (column 11), using Schmulovitz' estimate of the number of covered workers divided by the numbers in column 4.

In a later report, NASI [2001] provided a third group of estimates for 1996-1999 using a revised Schmulovitz methodology that incorporated state-by-state estimates of the effect of statutory requirements on unemployment and compensation insurance coverage. Using this new methodology, NASI estimated the number of covered jobs (column 10). Dividing estimates of the covered population based on the revised methodology with those of column 4 produced marginally higher estimates of the fraction covered, in the range of $85-87 \%$. The NASI estimates are consistent with the fractions estimated by the legal model.

However, since no published reports were found containing the actual data used to estimate the relationship between workers' compensation and unemployment insurance coverage, two additional estimates of the fraction covered by workers' compensation were made. The fourth estimate uses data from the OWCP [yearly]. Data were abstracted from reports covering the period 1995-1999 (the actual calendar period reported varied among the states) and the resulting estimates are reported in Table II. Table II uses data only from the 23 states that reported non-duplicate values for total and covered workers in at least 2 of the 4 years reviewed because the use of duplicate values from year to year suggested that estimates were not independent. Sixtynine of the possible 204 paired-values, involving 23 states,
TABLE II. Percentage of Workforce Covered by Workers' Compensation, 1995-1999 for States That Reported at Least Two Annual Non-Duplicate Datasets Over the Period 1995-1998

\begin{tabular}{lcccc} 
State & \% cov95 & \% cov96 & \% cov97 & \% cov98 \\
\hline California & 96.8 & & 93.7 & 94.6 \\
Connecticut & 91.7 & 92.0 & 92.0 & 92.0 \\
Georgia & 94.6 & & 91.9 & 94.9 \\
Hawaii & 87.9 & 85.5 & 94.3 & 94.3 \\
lowa & 97.0 & 97.0 & & 92.1 \\
Maine & 100.0 & & & 100.0 \\
Minnesota & 88.3 & 88.5 & 88.7 & 98.8 \\
Missouri & 81.5 & 83.0 & 83.0 & \\
Nebraska & 96.9 & & & 98.1 \\
Nevada & 48.1 & 48.1 & 44.3 & 44.3 \\
New Jersey & 84.3 & 84.1 & 89.1 & 91.6 \\
New Mexico & 83.7 & 83.7 & 85.5 & 82.9 \\
North Dakota & 81.8 & 83.1 & & \\
Ohio & 95.1 & 95.8 & $\mathrm{a}$ & $\mathrm{a}$ \\
Oregon & 91.2 & 94.4 & 95.0 & 95.2 \\
Pennsylvania & 96.1 & 89.9 & 90.2 & \\
Rhode Island & 91.9 & 85.5 & & 92.5 \\
Texas & 78.9 & 80.0 & & 80.0 \\
Utah & 96.8 & & 95.6 & 96.9 \\
Virginia & 93.5 & & & \\
Washington & $\mathrm{b}$ & $\mathrm{b}$ & 90.9 & 91.1 \\
West Virginia & 87.1 & & 81.2 & 96.8 \\
Wisconsin & 101.5 & 89.6 & & 90.0 \\
Combined & 89.3 & 85.8 & 87.1 & 87.7 \\
\hline
\end{tabular}

${ }^{\mathrm{a} C}$ Count excluded workers covered by self-insured employers.

${ }^{b}$ Count probably excluded workers covered by self-insured employers.

met these criteria. The southeast region of the country is somewhat under-represented in this sub-sample. The average percentage of states' workforces covered by workers' compensation ranged from 85.8 to $89.3 \%$. One of the authors of the current study (BZ), whose responsibilities include preparation of the estimate for Minnesota, expressed a strong reservation about doing comparisons state-by-state using OWCP data because OWCP provides no guidelines for construction of the estimate so that the groups tallied may vary from state to state. Moreover, some groups such as graduate students and volunteers are covered by workers' compensation but not by unemployment compensation. However, the senior author felt that the data are useful, so long as they are viewed only as confirmatory of estimates derived from better techniques.

The fifth estimate reports previously unpublished data provided by BLS (Commissioner Katherine G. Abraham, Personal Communication: 01/16/01) upon request after members of the ECI survey group indicated that they were unaware of the location of existing data runs that would verify the fraction of workers covered by workers' 
compensation. The ECI survey is a two-stage sample, the first of establishments in a cross-area- and cross-industry-based sample and, at the second stage, of occupations at the most narrowly-defined level [BLS, 1999b]. Table I indicates that, among the uncounted persons, the self-employed and agricultural workers account for less than $10 \%$ of jobs, with some overlap between the two groups. Data indicate that during the period 1990-2000 the other uncounted groups, private household workers [BLS, 2003d] and Federal Government workers [BLS, 2001a] represented 0.7-1.0\% and $2.1-2.2 \%$ of the total workforce, respectively. Thus, the ECI survey covers approximately $85-90 \%$ of US jobs. In addition, the uncounted federal workers are covered by the Federal Employees' Compensation Act [FECA, 1993].

Since the sampling unit in the ECI survey is an establishment/occupation cell and not all employees in an establishment, BLS' analysis estimated the number of workers who belonged to establishment/occupation cells that had coverage. This approach is consistent with the legal requirement that an employer cover all employees when the statute mandates coverage for an employer. Data were taken from the March 2000 survey. Respondees representing about $5 \%$ of employment failed to provide usable data. BLS estimates that $98.9 \%$ of employment (jobs) in the ECI survey was in establishments with workers' compensation coverage. The percentage varied from $100 \%$ in the Northeast states to $97 \%$ in Southern states. The structure of the sample did not support individual state estimates. Moreover, the precision of the regional estimates was not calculated, although BLS thought the "sample error for most to be large."

Thus, five different approaches indicate that a very high fraction of jobs in the United States provide workers' compensation coverage for the worker. The best estimate comes from the BLS special run with ECI survey data because it is derived directly from data in a carefully designed survey. Essentially all the workers in jobs in the survey had such insurance coverage. Other data noted in this section indicate that the job categories excluded from the ECI survey-the self-employed, farm workers, and household workers (also generally excluded from mandatory coverage under state workers' compensation statutes)—represent about $10 \%$ of jobs. The other group not in the ECI survey, federal workers, have their own compensation insurance. Thus, the special run indicates that a minimum of $90 \%$ of all jobs in the country have workers' compensation insurance coverage. The other estimates of coverage are somewhat lower, in the range of $85-90 \%$ of jobs covered, but are probably somewhat less reliable because they require combining the results from two different federal surveys, each with its own sampling strategy.

Moreover, jobs without coverage are not scattered randomly throughout the workforce, but are largely confined to four employed groups: the self-employed, agricultural workers, household workers and, in mostly Southern states, supra, employees of very small companies. Studies of the natural history of DAFW work injuries should consider that loss of ascertainment of study cases through compensation databases will be higher in some industries than in others, e.g., manufacturing v. construction ( $\sim 2$ vs. $\sim 16 \%$, respectively, in 1998) [BLS, 1999a]. This could bias coefficient estimates for main effects (e.g., industry, occupation, or injury type) and/or interactions in generalized linear models with DAFW as the outcome variable.

\section{PART II. FRACTION OF WORKERS WITH DAFW WORK INJURIES WHO MEET STATE WAITING TIMES FOR WAGE COMPENSATION (INDEMNITY) PAYMENTS}

Workers with DAFW work injuries who fail to satisfy waiting period requirements for wage compensation and receive only medical payments would contribute a negligible fraction of DAFW. In Michigan in 1990, for example, the medical payment only cases ineligible for wage compensation would have added less than $2 \%$ to the total DAFW for which compensation was paid, assuming that each such case had one-half the number of DAFW required for wage compensation eligibility (7 days) [Oleinick et al., 1993]. In Minnesota, in the same year and with a waiting period of 3 days, the medical payment only cases would contribute about $3 \%$ to the compensated missed work-time [Berry et al., 2001]. This estimate for Minnesota of 3\% is also approximate because it assumes that each such worker had one-half the 3 DAFW required for eligibility. In Wisconsin, with a waiting period of 3 days, Galizzi and Boden [1996] noted that workers with work injuries who were off work for at least a month accounted for $98 \%$ of time off work, although it does not appear that the contribution of workers with time off less than the required waiting period were included in the calculation.

Second, some work suggests that the factors affecting return-to-work in the immediate post-injury period are, at least in part, qualitatively different from those operative in the later stages of recovery from injury. Several investigators have documented this time dependence. Oleinick presented limited data that the association between younger age and earlier return-to-work operated to shift the age distribution of the compensated sub-group to older workers compared to the total work-injured group [Oleinick et al., 1996a].

Several other outcome studies using workers' compensation data also indicate that covariate effects vary by the interval since injury. Volinn, using multiple logistic regression with data from Washington State, investigated the association of covariates with chronicity and included several scales of occupational characteristics [1991]. The study documented differences in covariate effects by injury period. Galizzi and Boden [1996] divided the disability period into 
an acute and chronic phase at 30 days. Using a Weibull model, they found that 13 covariates were associated with return to work during the acute phase and that 12 of these were also associated with return to work in the chronic phase. Comparison of the values for the covariates in the two periods reveals that the magnitude of the significant effect differs and may even reverse in the two periods.

Similarly, Oleinick et al. [1996b] divided the post-injury period for back injuries into an acute and chronic phase with the cut point at 8 weeks. All workers eligible for compensation were used in a Cox analysis to identify factors affecting the return-to-work in the acute phase. The analysis identified six covariates as affecting return-to-work. A second Cox analysis, using only those workers whose initial work disability lasted longer than 8 weeks identified only two of the six factors as exerting an influence during this period. In a table included in Figure 2 of this reference, exponents are given for both phased and non-phased Cox analyses for representative covariate patterns. There are differences in the relative hazard estimate between the two different analytic approaches.

In part, differences in estimated covariate effects between studies could reflect differences either in the distribution of various injuries in the study populations or in the selection of cut-points to divide the acute and chronic recovery periods. The Galizzi study, for example, classified all injuries as objective (e.g., amputations, burns, fractures, etc.), subjective (diseases, sprains/strains, mental disorders, etc.), or other (multiple or other injuries) while Oleinick looked only at ANSI-coded back injuries. The subjective group included all sprains/strains, regardless of part of body affected. Galizzi's use of a single cut-point at 30 days for all types of injuries may obscure important differences in the times spent in the acute and chronic phases by sprains/strains at different body sites. In unpublished data from Michigan involving back sprains/strains developed in the course of preparing the back injury outcome paper [Oleinick et al., 1996b], we found that covariate effects in the acute period persisted throughout the period of 4-8 weeks and then changed to those identified in the chronic phase.

In a recent extensive review of the factors affecting the duration of work disability, Krause discussed the development of data on the relationship between disability phase and covariate effect and concluded that "the failure to stratify analyses according to work disability phase may lead to the masking of important risk factor effects" [Krause et al., 2001].

Since wage compensation data for DAFW contain information on almost all the DAFW experienced by injured workers who file any type of claim and since covariate effects appear to be specific, at least in part, to a particular interval following injury, compensation databases can help us to understand the factors that affect DAFW beyond the maximum waiting period. Moreover, if studies were standardized to this maximum interval, then results in various states might be generally applicable. Studies that include data from the eligibility waiting period following injury could help explain the important trend toward more restricted workday cases and away from DAFW cases [Ruser, 1999]. However, in the view of these investigators, the absence of such early data does not diminish the utility of available data for the study of later disability phases. If studies were to document that the trend toward accommodating work-injured employees by "light duty" work included cases that would otherwise have had prolonged DAFW, then that could affect the interpretation of significant covariates identified by analysis of compensation databases.

The present discussion indicates that, in light of the potential impact of differing compensation eligibility periods on the values of covariates affecting outcome, standardization is appropriate. Given the distribution of eligibility periods in the various states, standardization of study group selection at the value of DAFW that assures eligibility in all states would yield some degree of comparability among study groups in different states.

However, as noted in the next section, eligibility for wage compensation depends not only on the statutory waiting period but also upon the counting conventions employed in each state that govern when the count starts and whether intervening weekends and holidays are counted. A review of the counting conventions of the 22 states with a 7-day waiting period [OWCP, 2002], currently the longest required period, is beyond the scope of this paper but in Michigan, for example, temporary total disability is first paid on the sixth DAFW following a work injury [MCL, 2003b] (eighth day of continuous disability, not counting the day of injury). Of course, where data are available for shorter DAFW following work injuries, it would be of interest to analyze this period separately and to compare covariate estimates. Study populations that might be used to look at the factors influencing the earliest post-injury period are potentially available in states that require detailed accident records either for all injuries, e.g., Florida, or for injuries that extend beyond the day of injury, e.g., New York and Pennsylvania [OWCP, 2002].

\section{PART III. THE FRACTION OF WORKERS WITH WORK-RELATED INJURIES THAT MEET THE DAFW ELIGIBILITY REQUIREMENT THAT APPLIES FOR WORKERS' WAGE COMPENSATION}

The data in the previous section indicate that the loss of information for cases not meeting the DAFW eligibility requirements for wage compensation is unlikely to affect covariate estimates in modeling work injuries with longer DAFW because covariate effects influencing DAFW appear to differ by time from injury. In contrast, if a large fraction of eligible injured workers with longer DAFW failed to receive 
wage compensation the generalizability of outcome data could be affected.

Statements in the recent literature suggest that a number of investigators share the perception that many eligible workers forego applying for wage compensation benefits. Thus, Boden et al. [2001] indicate that "many injured workers ... conclude that it is better not to file for workers' compensation benefits," Dembe [2001] notes "available data indicates that injured workers may be reluctant to report work-related ailments," while Reville et al. [2001] conclude that information on "incidence and costs" is "significantly underestimated" because "information on injuries that do not result in claims is unavailable." All of the references cited refer generically to "injuries." Moreover, the authors do not consider whether the underreporting is general or applies preferentially to "medical only" payment cases or to those eligible for wage compensation because they meet the disability waiting periods for injuries or to occupational illness cases where the causal connection may not be as apparent.

Moreover, none of the studies relied upon by these authors establish that under-reporting occurs in the group of occupational injuries eligible for wage compensation on the basis of DAFW. First, two studies cited by these authors compare case ascertainment in states that mandate physician reporting of work injuries or illnesses (Connecticut [Morse et al., 2001], Michigan [Biddle et al., 1998]) with data in that state's compensation database. However, neither study provides any information on the DAFW distribution of physician-identified cases so the fraction of eligible cases actually applying for or receiving wage compensation is indeterminate. Second, several studies provide information on the fraction of cases with any lost work-time (2.3-14.7\%) [Jefferson, 1996; Park et al., 1996; Silverstein et al., 1997; Pransky et al., 1999] but provide no information on the fraction of DAFW cases meeting eligibility criteria.

In contrast, limited data from several other studies indicate that workers' compensation databases may compensate a large fraction of workers whose DAFW following a work injury satisfy the eligibility criterion. In two studies [Frumkin et al., 1995; Keogh et al., 2000], 75-83\% of eligible injured workers either applied for or received wage compensation. A third study [Hensler et al., 1991] indicates only that "more than half" of workers with new injuries producing more than seven DAFW received wage compensation. These three studies had limited sample sizes, did not yield uniform results, and the issue of completeness of ascertainment of eligible DAFW cases by the compensation system was not an explicit objective of the study so that no firm conclusions are possible. However, they do suggest that it would be useful to make a distinction between the subgroup of work injuries eligible for wage compensation because of sufficient DAFW and other subgroups of work injuries or illnesses.
Two recent studies address the issue. Shannon reported that 133 workers in a national survey had had a work injury producing "time off" [2002]. Of these, $40 \%$ did not file for wage compensation. However, correspondence with the authors indicates that any time off was classified as time off. Since some Canadian provinces do not provide wage compensation for the day of injury and a few require more than one DAFW (not counting the day of injury) [Chamber of Commerce, 1999] workers who required time off for medical attention on the day of injury, but no later DAFW, would be included in the $40 \%$. The study also did not collect data on the duration of DAFW.

Rosenman et al. [2000] reported the results of a telephone survey of "1,598 individuals diagnosed with neck, upper extremity, and low back work-related [repetitive] musculoskeletal disease" whose diagnoses were reported by their physicians, as required by state law [MCL, 2003a]. Of the 313 workers who reported being off 7 or more consecutive days [the Michigan waiting period], 24.6\% did not file for wage compensation. This study appears to be the most direct evidence of under-reporting of claims eligible for compensation.

However, the relevance of this study to the question of completeness of ascertainment of work injuries eligible for indemnity payments is unclear. The authors noted that "relatively few reports involving back disorders were received (only $7 \%$ of reports) because... back disorders [including cervical disorders] are considered injuries and are not required to be reported [compared to the $23 \%$ of all DAFW injuries and illnesses in Michigan in 1997] [BLS, 1998]" and it is unclear whether their back cases were representative of all back injuries. Thus, their results are strictly applicable to upper extremity repetitive stress disorders, a subgroup that accounts for some 5\% of DAFW injuries in the BLS annual survey reports for Michigan in 1995 and 2000 (special BLS data runs-nature by part of body, Michigan, 1995 and 2000). Admittedly, the BLS coding scheme is not based on clinical exams so that some traumatic injuries would likely be re-classified as repetitive trauma injuries on the basis of clinical evaluations and so increase the impact of underclaiming. However, without complete diagnostic information for the work-injured population and an estimate of the completeness of ascertainment of all indemnity eligible cases, it is difficult, if not impossible, to place their result in a proper perspective.

An estimate of the sensitivity of ascertainment of eligible DAFW cases by a state-wide compensation system could be obtained directly by comparing a statewide enumeration of worker injury or illness DAFW cases meeting a state's waiting period criteria with a roster of wage compensation cases whose DAFW qualified them for wage compensation. To these investigators' knowledge, no such enumeration and comparison has been done because the data are simply unavailable. 
In the text that follows, the following abbreviations are used and are presented here for convenient reference:

TTD $=$ temporary total disability, DAFW during the acute, recuperative and rehabilitative phases following an occupational injury or illness.

$\mathrm{TPD}=$ temporary partial disability, restricted work or "light duty" jobs, reduced workdays or workweeks during the same post-injury periods noted in TTD.

PPD $=$ permanent partial disability, a reduction in work capacity attributable to a permanent functional or anatomic loss once maximum medical improvement has occurred following an occupational injury or illness.

PTD $=$ permanent total disability, total work disability resulting from an occupational injury or illness.

However, by comparing aggregate data in two existing databases an approximate solution can be obtained, notwithstanding the fact that the two databases can not be linked directly. The underlying strategy is to adjust the counts in each of the databases, the BLS sample-based count of DAFW injuries in Minnesota in the annual survey of occupational injuries and illnesses and the Minnesota workers' compensation claim count of cases receiving either temporary total disability (TTD) or permanent total disability (PTD) payments for DAFW in the same year. This adjustment eliminates differences in total counts produced by the use of different case ascertainment methods with the same underlying reference population—work injury cases with DAFW.

Limited data suggest that data collection in the two systems is not closely linked, though it might be anticipated in this age of computers that the BLS request for supplementary data on DAFW injuries among the OSHA log cases would routinely be met by the employer with data from indemnity claim files when claims were filed. In Minnesota, however, anecdotal evidence from the staff that codes the state sample indicates that sampled employers use workers' compensation First Reports of Injury to provide the required information for BLS DAFW cases in about $30 \%$ of cases.

Investigators in the Research and Statistics unit in the Minnesota Department of Labor and Industry noted that the BLS rate for all DAFW cases was $13 \%$ higher than the wage indemnity claim rate over the period 1984-1998 [Berry, 2000; Zaidman and Phan, 2002]. Berry noted that, considering the BLS cases with 1-2 DAFW who did not meet the waiting period and the compensation cases without an indication of wage payments for DAFW, the BLS DAFW should have been some 30\% higher. Although the supporting data for this estimate was not provided in the report, it was based on the assumption that BLS cases with 1-2 DAFW do not receive wage payments for DAFW. He also suggested that underreporting occurs in the BLS data and discounted overreporting of compensation claims because the rates were based on cases where payment was authorized.

This report extends the work of the Research and Statistics unit in the Minnesota Department of Labor and Industry by providing quantitative estimates for the adjustments. Agreement between counts in the two systems would support the conclusion that the two methodologies, after adjustment, count the same phenomenon - the number of DAFW injuries meeting the eligibility requirements for wage replacement for DAFW. The alternative, that differing biases that may be associated with the different methodologies yield nearly identical results in two loosely linked systems, seems an unlikely scenario. Until better data come along, the proposed approach represents the most relevant current evidence.

The BLS DAFW counts are adjusted in columns 2-5 of Table III and compared with adjusted Minnesota indemnity claim numbers derived in the next five columns. The BLS DAFW counts are statewide estimates derived from an annual sample of private industry, state and local government establishments. For all practical purposes, the adjusted numbers represent traumatic or repetitive stress injuries because only $1-2 \%$ of occupational injuries and illnesses are coded as occupational illnesses, regardless of whether the BLS [2002] or National Council on Compensation Insurance [Minnesota Department of Labor \& Industry, 2003] coding schemes are used.

The BLS DAFW cases shown in columns $2-5$ in Table III are divided into cases with 4+ DAFW (four or more) and those with fewer DAFW because cases with 4+ DAFW always meet the waiting period requirements for eligibility for wage compensation measured by DAFW in Minnesota. Under the statute [Minnesota Statutes, 2002], disability for purposes of DAFW compensation eligibility commences "on the first calendar day or fraction of a calendar day that the employee is unable to work" [including the day of injury] and is payable beginning on the fourth day after the disability commences. Since BLS did not count the day of injury in determining DAFW during the period noted [BLS, 2001d], the minimum number of DAFW assuring eligibility is 4 . Thus, a worker who is injured on Monday, completes work that day and is continuously work-disabled beginning the next day (some $30 \%$ of Minnesota cases began their work disability on the day after the injury in the period 19951999 ) is eligible for 1 day of wage compensation payments on the fourth day of disability, or Friday. This individual would show up, in the BLS survey, with 4 DAFW. If the worker returned to work on Friday, in contrast, no compensation would be payable and the worker would be reported to BLS as having 3 DAFW.

Column 2 gives the total Minnesota DAFW injury and illness case counts from the annual state reports based upon 


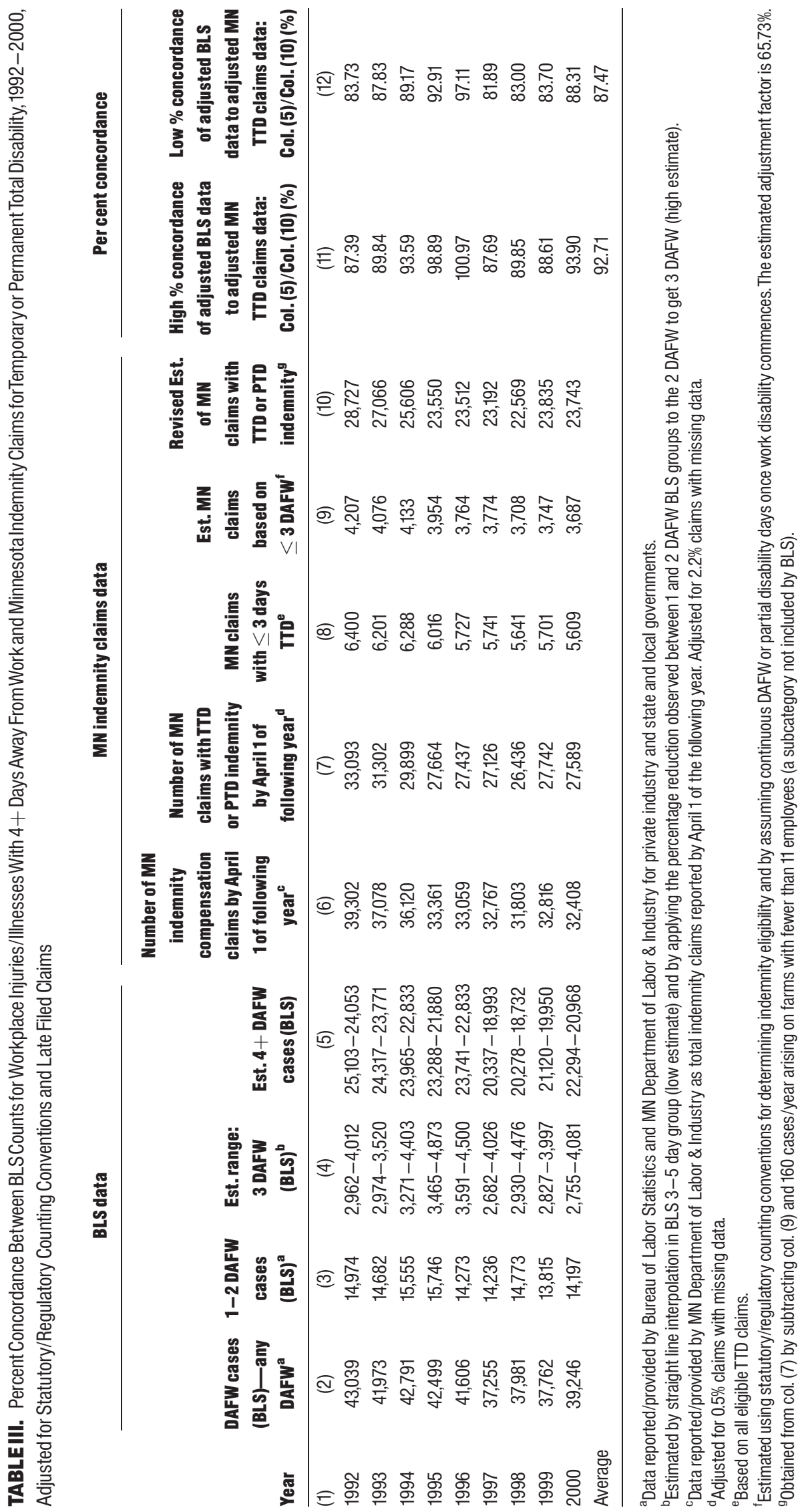


the BLS survey [BLS, 2001c]. Column 3 combines the individual counts for the 1 and 2 DAFW categories. Column 4 gives a range estimate for the number of cases with 3 DAFW because the survey provides results only for the category $3-$ 5 DAFW. Two estimating techniques yield the range indicated. The smaller value is produced by straight-line interpolation of the number given in the 3-5 DAFW category. The larger estimate is obtained by multiplying the 2 DAFW case number by the percentage decrease observed between the 1 DAFW and 2 DAFW categories because there is a rapid fall-off in cases by DAFW category in the early days after injury as workers with minor injuries rapidly return to work [Oleinick et al., 1996a]. Finally, column 5 gives the range of the 4+ DAFW count that results from subtracting the sum of column 3 and the high or low estimates in column 4 from column 2 .

The number of Minnesota indemnity claims with payments for DAFW as of April 1 of the year following the injury year are shown in columns 6-10. April 1 was chosen as the cut-date because the BLS survey is distributed in midto late January with a first due date of March 1st. In Minnesota, approximately $40 \%$ of forms are returned by March 1st, two-thirds by early May, with an ultimate return rate of $99.5 \%$. Between March 1 and April 1, an annual average of 93 new indemnity claims from the previous year were first paid TTD/PTD. Some of these additional claims could have been filed after the BLS form was returned. On average, 357 new cases with TTD/PTD payments were filed after April 1 of the year following the injury year and December 2002, when the data run was done, for each of the study years 1992-2000.

All indemnity claims are tallied in column 6 . Column 7 gives the count after the approximately $14-15 \%$ of indemnity claims without payments for TTD or PTD for DAFW are removed. PTD cases are rare and account for approximately $0.1 \%$ of claims. The $14-15 \%$ includes some $5 \%$ with only temporary partial disability (TPD) payments reflecting reduced workweeks or workdays or "light duty" work paying less than their previous wage, some $0.3 \%$ of cases with both TPD and permanent partial disability (PPD) for anatomic or functional loss but without DAFW qualifying for TTD, some $3 \%$ of cases with PPD payments only, and some $4-6 \%$ of cases with stipulated agreements, with or without TPD or PPD.

The next adjustment involves subtraction from column 7 of those cases that became eligible for indemnity payments with less than 4 DAFW. Cases can be eligible with fewer than 4 DAFW because of the counting conventions used by Minnesota to determine eligibility. The count in column 8 is based upon a cross-tabulation of weekday of injury by days from injury to first day of disability for compensation purposes (first DAFW or partial disability day) for cases with less than 4 days of TTD payments.
Approximately $66 \%$ of cases that receive TTD payments for less than 4 days are estimated to be eligible on the basis of less than 4 DAFW (column 9). This percentage was obtained by identifying the possible eligibility scenarios and then by weighting the scenarios with the percentages observed in the cross-tabulation. The estimate assumes that work disability for purposes of determining compensation eligibility is continuous once it begins, regardless of whether it is TTD or TPD since Minnesota counts both, and that there is at least one DAFW in the eligibility period so that the case would have been included in the BLS count. For example, a worker injured on Thursday who leaves work that day and misses either all or part of the workday on Friday and all of Monday would have 1 or 2 DAFW in the BLS scheme, and receive wage payments for 1 day because the eligibility count is based on calendar days and includes the weekend if there are disability days on either side. In addition, at least one scenario with 1 DAFW work in the BLS scheme qualifies for compensation. This occurs in $4.3 \%$ of all compensation cases with 3, or fewer, days of TTD and arises when the worker is injured on Friday, leaves work that day, and misses work on Monday. All cases receiving payments for 4, or more, days of TTD/PTD must, of necessity, have at least 4 DAFW. No data is available on the number of cases where eligibility for indemnity arises solely from restricted workdays that are then followed by DAFW resulting in payment of TTD, but the authors believe that such a scenario would occur most frequently in claims with payments for fewer than 4 days TTD and so would act to increase the estimate in column 9.

The final estimates of Minnesota indemnity claims with 4+ DAFW for comparison with the comparable BLS estimates are shown in column 10. One additional adjustment has been made in this column. One hundred and sixty cases have been subtracted from each count because this is the average annual number of claims originating on farms with fewer than 11 employees, a group not surveyed in the BLS count [BLS, 2002]. It was not possible to reduce this number further by removing claims arising from injuries suffered by volunteers for various organizations such as rural fire departments because such cases are not readily identified in the database.

The percentage concordances of the BLS 4+ DAFW group to the Minnesota TTD/PTD claims based on the same criterion are shown in columns 11 and 12 . They range from a low of $81.89 \%$ to a high of $100.97 \%$. Over the years studied, the range of the average values is $87.47-92.71 \%$. For the reasons that follow, we believe that the true percent concordance may actually be closer to $92-97 \%$, a level that indicates that the sensitivity of workers' compensation databases is quite adequate for most epidemiologic studies.

In the case of the BLS data, there are three reasons for believing that one, or both, values in the range given in column 5 are low. First, and most important, is data from the OSHA Data Initiative (ODI) [Eastern Research Group, Inc 
and National Opinion Research Center, 2002]. In 1995, the Occupational Safety and Health Administration (OSHA) established the ODI to obtain data on occupational injuries and acute illness from establishments in high-hazard industries. This data serves as the basis for targeting enforcement and compliance assistance [OSHA, 2002]. The number of establishments in the reference population has grown from 80,000 in a limited range of high-hazard industries in 1995 to 127,859 establishments in 2000 in what is now a standard ODI universe intended to facilitate comparisons between years beginning with 2000 . The ODI, like the BLS survey, is based on the OSHA Form 200, the employer's annual log of occupational injuries and illnesses required by statute.

To monitor the quality of data submitted on the annual survey, OSHA created an ongoing audit program. The audit population was obtained from a sample stratified by SIC, region, and employment size and sampled by a systematic selection procedure. In 2000, the reference population of highhazard establishments accounted for some $46 \%$ of BLS DAFW injuries and contained approximately $30 \%$ of the employed workforce. There were 390 establishments in the original sample. Of these, 242 provided usable data; 45 were out of business, not in high hazard industries, represented duplicates or survey forms were undeliverable; 37 were in non-participating states; 30 refused participation; 26 represented small establishments with less than 40 employees; 7 establishments had data problems on audit and three audits were never undertaken for various reasons. 242 of the 263 establishments required to meet the audit study's power specification for detecting an accuracy of employer recordkeeping by establishment of $\geq 95 \%$ provided useful data. Auditors reviewed company records on site to determine whether injuries with lost workdays were misclassified as nonlost workday cases or were omitted from the log entirely. The results of the audit indicated that $12 \%$ of cases with DAFW were misclassified-either entered as non-lost workday cases $(5 \%)$ or omitted from the $\log (7 \%)$ (this percentage is net of the fraction of $<1 \%$ of cases that were erroneously recorded as lost workday cases instead of non-lost workday cases). In the previous 2 years, with a less inclusive sampling universe the percentages were $16.6 \%$ and $11.4 \%$ for 1999 and 1998 , respectively.

Unfortunately, this percentage is not directly applicable to the data in Table III. First, the ODI involves only highhazard industries in contrast to the broad SIC representation in the BLS survey. To the extent that ODI data are used to target enforcement activities, there may be some tendency to minimize the number reported to OSHA. Second, the percentages specified are un-weighted for establishment size. The percentage of establishments reporting more than $95 \%$ of their lost workday cases as lost workday cases varies monotonically by size of establishment, with $96 \%$ of establishments with 40-99 employees meeting this criterion compared to $84 \%$ for establishments with $\geq 250$ employees.
The second reason for believing that the BLS estimates in column 5 are low is that the method used in column 4 to produce the higher estimate of cases with 3 DAFW probably over-corrected the value somewhat because the percentage drop between the second and third day is likely to be smaller than the drop seen in the first 2 days.

Third, there are published reports that suggest that the smallest establishments ( $<11$ employees) may underreport injury cases in the BLS survey [Oleinick et al., 1995; Okun et al., 2001] and the National Institute of Occupational Safety and Health concurred in this suggestion in its annotated submission during the course of the rule-making that revised OSHA's Occupational Injury and Illness Recording and Reporting Requirements rule [OSHA, 2001]. If one assumes that the incidence rate for the smallest establishments is equal to the annual rates for establishments with 11-49 employees (in Minnesota, the rates for this latter group approximate the statewide rates) and adjusts the overall count using count and incidence density data by establishment size provided in a data extract from BLS, the estimates in column 5 would increase by $1-3 \%$.

Similarly, the estimates for the number of Minnesota indemnity cases with payments for DAFW as TTD or PTD may be understated. This is because none of the cases with only stipulated agreements were included and some may contain payments for DAFW that were recorded in the OSHA $\log$. Stipulated agreements represent a comprehensive and final settlement of employer liability for the injury. They involve a lump sum payout in which the amounts paid for DAFW are not distinguished from payments for TPD or PPD or for medical benefits. The group with stipulations is heterogenous. The first subset involves cases where the disagreement is over the size of the fraction of permanent disability that determines PPD payments and there have been no earlier TTD/PTD payments. The second subset involves cases where the employer agrees to a modest payment but disputes the work-related origin. Still a third subset involves cases where any type of indemnity payments for DAFW is simply rolled into the total paid and not itemized. Only the last subset has relevant TTD payments. Even if this last subset represented one half of the stipulated group, their contribution would be offset by the suggested effect of undercounting among the very smallest employer group in the BLS survey. It is also possible that some of the approximately $8.3 \%$ of indemnity claims receiving TPD and/or PPD payments qualified with one or more DAFW and would have been counted by BLS.

On balance, the known factors affecting undercounting in the BLS system outweigh the conjectured undercounts in the indemnity claims. In particular, the ODI data suggest that the concordance of equivalent BLS counts with Minnesota indemnity cases may actually approximate $92-97 \%$, if one makes the conservative assumption that a correct extrapolation of audit results would produce a $5 \%$ undercount rather 
than the unadjusted figure of $12 \%$ in light of the methodological issues raised and the conjectured undercounts in claims data. Even more importantly, even without this assumption there is nothing in the data to support the belief that DAFW injuries eligible for wage compensation are under-ascertained in the workers' compensation system.

Does underreporting of work injuries occur? Some literature suggests that underreporting occurs, particularly for occupational diseases. However, the critical methodologic issue is whether underreporting of occupational diseases renders workers' compensation administrative databases inappropriate for the study of the occurrence and outcome of occupational injuries with DAFW in light of the concordance rate reported. The high degree of concordance suggests that such administrative databases, at least in some jurisdictions, are excellent sources for epidemiologic studies of work injuries.

\section{SUMMARY AND CONCLUSIONS}

Employers provide workers' compensation coverage for all, or nearly all, workers for whom such coverage is mandated by statute. Workers (98.9\%) covered by unemployment insurance, representing approximately $85-90 \%$ of all jobs, have such coverage according to a special data run by BLS. This estimate is consistent with estimates from several other sources. The fraction of workers covered varies between industries and between occupations and reflects the fraction of the workforce that are members of the groups excluded from mandatory coverage. Thus, almost all manufacturing industry employees are covered $(\sim 98 \%)$, while a smaller percentage of construction industry workers are covered $(\sim 84 \%$, varies depending on the size criteria in the statute).

Omission of data on "medical payment only" cases (medical payments and/or too few DAFW to qualify for wage compensation) is estimated to reduce the available information on DAFW by less than 3\%. Moreover, several studies suggest that factors affecting a return to work following a work injury with DAFW differ by time from injury so that the loss of data on the days immediately following the injury would not bias the coefficient estimates in models based on data from later injury phases.

Comparison of data from Minnesota for DAFW cases in the annual BLS survey and wage indemnity claims in the Minnesota Department of Labor and Industry indicate $92-$ 97\% concordance between counts of work injuries and illnesses reported as producing $4+$ DAFW in the annual BLS survey and the number of Minnesota wage compensation claims whose eligibility for payment is based upon $4+$ DAFW. The fact that the two databases agree so closely suggests that the sensitivity of workers' compensation databases, based on the Minnesota database, is quite sufficient to warrant their use in studies of the natural history of workplace injury and that the BLS survey also has high sensitivity for workplace injuries with 4+ DAFW. The issue of whether compensated DAFW represents the full social impact of a work injury is distinct analytically and is reserved for a subsequent paper in the series.

\section{ACKNOWLEDGMENTS}

We thank Katherine G. Abraham, then Commissioner of the federal Bureau of Labor Statistics and the staff of the Employment Cost Index Survey for special tabulations that document the extent of workers' compensation insurance coverage for jobs covered by unemployment insurance. In addition, we thank William L. Weber, former Assistant Commissioner for Safety, Health and Working Conditions at the federal Bureau of Labor Statistics, Dr. John Ruser, formerly a Research Economist with the Compensation Research and Program Development at BLS and the staff of the BLS Annual Survey of Occupational Injuries and Illnesses for providing injury counts by establishment size for Minnesota and several other Great Lakes States. While the foregoing individuals provided technical insights and data extracts, any errors in the use or interpretation of these data are solely the responsibility of the authors.

\section{REFERENCES}

Amirault T. 1997. Characteristics of multiple jobholders, 1995. Mon Labor Rev 120(3):9-15.

Berry D. 2000. Minnesota workplace safety report: Occupational injuries and illnesses, 1998. St. Paul, MN: Research and Statistics Minnesota Department of Labor \& Industry. URL: http://www.doli. state.mn.us/pdf/98safrpt.pdf.

Berry D, MacDonald C, Zaidman B. 2001. Minnesota workers' compensation system report, 1999. St. Paul, MN: Minnesota Department of Labor \& Industry. URL: http://www.doli.state.mn.us/pdf/ wcfact 99 .pdf.

Biddle J, Roberts K, Rosenman KD, Welch EM. 1998. What percentage of workers with work-related illnesses receive workers' compensation benefits? J Occup Environ Med 40(4):325-331.

Boden LI, Biddle EA, Spieler EA. 2001. Social and economic impacts of workplace illness and injury: Current and future directions for research. Am J Ind Med 40:398-402.

Bureau of Labor Statistics (BLS). 1998. Survey of occupational injuries and illnesses, 1997. Table 6. Incidence rates for occupational injuries and illnesses involving days away from work per 10,000 full-time workers for selected characteristics and industry division, 1997. Michigan-private industry. Washington, DC: U.S. Department of Labor. http://michigan.gov/documents/CIS_WSH_97c_dpri_27742_7.pdf.

Bureau of Labor Statistics (BLS). 1999a, 1997, 1996, 1990. Employment and wages annual averages, 1998, 1996, 1995, 1989. Bulletin 2525, 2494, 2483, 2373. Washington, DC: U.S. Department of Labor. 1998 data: SZ000098.ZIP, http://www.bls.gov/cew/home.htm\#data (flat file-FTP).

Bureau of Labor Statistics (BLS). 1999b. Employment cost indexes, 1975-1998. Bulletin 2514. Washington, DC: U.S. Department of Labor (see also http://www.bls.gov/opub/mpbls/ocwc001.htm\#d).

Bureau of Labor Statistics (BLS). 2000. Employment and earnings. Table 1. Bulletin 2546. Washington, DC: U.S. Department of Labor. URL: LFU 11000000, http://data.bls.gov/cgi-bin/srgate. 
Bureau of Labor Statistics (BLS). 2001a. Labor force statistics from covered employment and wages (CEW) series ID EWUUS0001010Z. URL: http://data.bls.gov/cgi-bin/srgate.

Bureau of Labor Statistics (BLS). 2001b. Labor force statistics from the Current Population Survey (1991-2001). Series Report LFU11102010000, 11102080000, 11102090000, 11104080000. Washington, DC: U.S. Department of Labor. URL: http://data.bls.gov/cgi-bin/srgate.

Bureau of Labor Statistics (BLS). 2001c. Occupational injuries and illnesses in the United States profiles data 1992-2000. Washington, DC: U.S. Department of Labor. V. 8.0 (2 CDs).

Bureau of Labor Statistics (BLS). 2001d. Occupational safety and health case and demographic data. URL: http://www.bls.gov/iif/oshcase1.htm.

Bureau of Labor Statistics (BLS). 2001e. The employment situation news release: Employment situation explanatory note. URL: http:// www.bls.gov/news.release/empsit.tn.htm.

Bureau of Labor Statistics (BLS). 2002. Workplace injuries and illnesses in 2001. Washington, DC: U.S. Department of Labor. URL: http://www.bls.gov/news.release/osh.nr0.htm.

Bureau of Labor Statistics (BLS). 2003a. Case and demographic characteristics for work-related injuries and illnesses involving days away from work, 2001. Table R67. Washington, DC: U.S. Department of Labor. URL: http://www.bls.gov/iif/oshwc/osh/case/ostb1222.pdf.

Bureau of Labor Statistics (BLS). 2003b. Labor force statistics from the Current Population Survey (1994-2002). Series Report LFU172000000. URL: http://data.bls.gov/cgi-bin/srgate.

Bureau of Labor Statistics (BLS). 2003c. Lost-worktime injuries and illnesses: Characteristics and resulting days away from work, 2001. Washington, DC: U.S. Department of Labor. URL: http://www.bls.gov/ news.release/osh2.nr0.htm.

Bureau of Labor Statistics (BLS). 2003d. Labor force statistics from the Current Population Survey. Series ID LFU11000000, LFU11176920000. URL: http://data.bls.gov/cgi-bin/srgate.

Chamber of Commerce. 1999. 1999 analysis of workers' compensation laws. Washington, DC: Chamber of Commerce of the United States.

Dembe AE. 2001. The social consequences of occupational injuries and illnesses. Am J Ind Med 40:403-417.

Eastern Research Group Inc., and National Opinion Research Center. 2002. OSHA Data Initiative Collection Quality Control: Analysis of Audits on CY 2000 Employer Injury and Illness Recordkeeping. Washington, DC: Office of Statistics, Occupational Safety and Health Administration.

Federal Employees' Compensation Act (FECA). 2000. 5 U.S.C. $\$ \$ 8101-$ 8193. URL: http://www.dol.gov/esa/regs/statutes/owcp/feca.htm.

Frumkin H, Williamson M, Magid D, Holmes JH, Grisso JA. 1995. Occupational injuries in a poor inner-city population. J Occup Environ Med 37(12):1374-1382.

Galizzi M, Boden L. 1996. What are the most important factors shaping return to work? Evidence from Wisconsin. Cambridge, MA: Workers Compensation Research Institute.

Hensler DR, Marquis MS, Abrahamse AF, Berry SH, Ebener PA, Lewis EG, Lind EA, MacCoun RJ, Manning WG, Rogowski JA, Vaiana ME. 1991. Compensation for accidental injuries in the United States. Santa Monica, CA: RAND-The Institute for Civil Justice.

Jefferson JR. 1996. Back pain and peripheral joint pain in an industrial setting. Arch Phys Med Rehabil 77:385-390.

Keogh JP, Nuwayhid I, Gordon JL, Gucer P. 2000. The impact of occupational injury on injured worker and family: Outcomes of upper extremity cumulative trauma disorders in Maryland workers. Am J Ind Med 38:498-506.
Krause N, Frank JW, Dasinger LK, Sullivan TJ, Sinclair SJ. 2001. Determinants of duration of disability and return-to-work after workrelated injury and illness: Challenges for future research. Am J Ind Med 40:464-484.

Leigh JP, Markowitz SB, Fahs M, Shin C, Landrigan PJ. 1997. Occupational injury and illness in the United States. Estimates of costs, morbidity, and mortality. Arch Intern Med 137:1557-1568.

Michigan Compiled Laws (MCL). 2003a. \$\$333.5601, 333.5611, 333.5623. URL: http://www.michiganlegislature.org/mileg.asp?page= getObject\&objName $=$ mcl-333-5611.

Michigan Compiled Laws (MCL). 2003b. §418.311. http://www. michiganlegislature.org $/ \mathrm{mileg}$. asp page $=$ getObject\&objName $=$ mcl418-311.

Minnesota Department of Labor \& Industry. 2003. Injury characteristics of indemnity claimants, injury-years 1999-2001. URL: http://www. doli.state.mn.us/injurychar.htm.

Minnesota Statutes $\$ 176.121 .2002$. Statute URL: http://www.revisor.leg. state.mn.us/stats/176/121.html.

Morse T, Dillon C, Warren N, Hall C, Hovey D. 2001. Capturerecapture estimation of unreported work-related musculoskeletal disorders in Connecticut. Am J Ind Med 39:636-642.

National Academy of Social Insurance (NASI). 2001. Workers' compensation: Benefits, coverage, and costs, 1999 new estimates and 1996-1998 revisions. Washington, DC: National Academy of Social Insurance.

Nelson WJ. 1988. Workers' compensation: Coverage, benefits, and costs, 1985. Soc Secur Bull 51(1):4-9.

Nelson WJ. 1992. Workers' compensation: 1984-88 Benchmark revisions. Soc Secur Bull 55(3):41-58.

Occupational Health and Safety Administration (OSHA). 2001. Occupational injury and illness reporting requirements: Final rule 66 federal register 5915, 5936.

Occupational Safety and Health Administration (OSHA). 2002. OSHA notice directive \#02-05 (CPL 2): Audit and verification program of 2001 occupational injury and illness records. Washington, DC: U.S. Department of Labor.

Office of Workers' Compensation Programs (OWCP). 2002. State Workers' Compensation Laws. Washington, DC: U.S. Department of Labor. URL: http://www.dol.gov/esa/regs/statutes/owcp/stwclaw/ stwclaw.htm.

Office of Workers' Compensation Programs (OWCP). Annual. State workers' compensation administration profiles. Washington, DC: U.S. Department of Labor.

Okun A, Lentz TJ, Schulte P, Stayner L. 2001. Identifying high-risk small business industries for occupational safety and health interventions. Am J Ind Med 39:301-311.

Oleinick A, Guire KE, Hawthorne VM, Schork A, Gluck JV, Lee B, La S. 1993. Current methods of estimating severity for occupational injuries and illnesses: Data from the 1986 Michigan comprehensive compensable injury and illness database. Am J Ind Med 23:231-252.

Oleinick A, Gluck JV, Guire K. 1995. Establishment size and risk of occupational injury. Am J Ind Med 28:1-21.

Oleinick A, Gluck JV, Guire KE. 1996a. Concordance between ANSI occupational back injury codes and claim form diagnoses and a lower bound estimate of the fraction associated with disc displacement/ herniation. Am J Ind Med 30:556-568.

Oleinick A, Gluck JV, Guire KE. 1996b. Factors affecting first return to work following a compensable occupational back injury. Am J Ind Med 30:540-555. 
Park RM, Krebs JM, Mirer FE. 1996. Occupational disease surveillance using disability insurance at an automotive stamping and assembly complex. J Occup Environ Med 38(11):1111-1123.

Pransky G, Snyder T, Dembe A, Himmelstein J. 1999. Under-reporting of work-related disorders in the workplace: A case study and review of the literature. Ergonomics 42(1):171-182.

Price DN. 1980. Workers' compensation: 1978 program update. Soc Secur Bull 43(10):3-10

Reville RT, Bhattacharya J, Sager-Weinstein LR. 2001. New methods and data sources for measuring economic consequences of workplace injuries. Am J Ind Med 40:452-463.

Rosenman KD, Gardiner JC, Wang J, Biddle J, Hogan A, Reilly MJ, Roberts K, Welch E. 2000. Why most workers with occupational repetitive trauma do not file for workers' compensation. J Occup Environ Med 42(1):25-34.

Ruser JW. 1999. The changing composition of lost-workday injuries. Mon Labor Rev 122(6):11-17.

Schmulovitz J. 1995. Workers' compensation: Coverage, benefits, and costs, 1992-1993. Soc Secur Bull 58:51-57.
Schmulowitz J. 1997. Workers' compensation: Benefits, coverage, and costs, 1994-1995 new estimates. Washington, DC: National Academy of Social Insurance.

Shannon HS, Lowe GS. 2002. How many injured workers do not file claims for workers' compensation benefits? Am J Ind Med 42:467-473.

Silverstein B, Stetson DS, Keyserling WM, Fine LJ. 1997. Work-related musculoskeletal disorders: Comparison of data sources for surveillance. Am J Ind Med 31:600-608.

Social Security Administration (SSA). Annual. Annual statistical supplement to the Social Security Bulletin. Washington, DC: U.S. Department of Health and Human Services.

Stinson JF. 1997. New data on multiple jobholding available from the CPS (1980-1991). Mon Labor Rev 120(3):3-8.

Volinn E, Van Koevering D, Loeser JD. 1991. Back sprain in industry: The role of socioeconomic factors in chronicity. Spine 16:542-547.

Zaidman B, Phan DN. 2002. Minnesota workplace safety report Occupational injuries and illnesses, 2000. St. Paul, MN: Research and Statistics Minnesota Department of Labor \& Industry. URL: http:// www.doli.state.mn.us/pdf/saferpt00.pdf. 